\title{
LA PRESCRIPCIÓN DE LA ACCIÓN DE LA ADMINISTRACIÓN TRIBUTARIA PARA EXIGIR EL COBRO DE LA DEUDA TRIBUTARIA: ¿ES INCONSTITUCIONAL EL DECRETO LEGISLATIVO 1421?*
}

THE EXTINCTIVE PRESCRIPTION OF THE CAUSE OF ACTION OF THE TAX ADMINISTRATION IN THE PROCEEDING OF COLLECTING A TAX DEBT: IS LEGISLATIVE DECREE 1421 UNCONSTITUTIONAL?

\author{
Luis Durán Rojo* \\ Pontificia Universidad Católica del Perú \\ Hugo Martín Arbieto Alfaro ${ }^{* * *}$ \\ Pontificia Universidad Católica del Perú
}

\begin{abstract}
After Legislative Decree 1113 came into force, the discussion regarding the constitutionality of the extinctive prescription of the cause of action for the tax administration in the proceeding of collecting a tax debt arose. Such debate originated because the prescription period began running before the legislative decree came into force.

In this article the authors explore constitutional foundation of extinctive prescription as well as they analyze the prescription of the cause of action for the tax administration collect a tax debt. faculty of collecting tax debts. Also, the authors examine the application over time of Legislative Decree 1113. Finally, they propose a proportionality test of the constitutional values in conflict.
\end{abstract}

KEYWORDS: prescription; tax debt collection; legal certainty; principle of equality; temporal application of rules.
Luego de la entrada en vigencia del Decreto Legislativo 1113, surgió la discusión jurídica sobre la constitucionalidad de la prescripción de la acción de la Administración tributaria para cobrar las deudas tributarias. Ello a raíz de que el cómputo del plazo de prescripción habría empezado a computarse antes de la entrada en vigencia de esa norma.

En este artículo, los autores indagan los fundamentos constitucionales de la prescripción, analizan la figura de la prescripción de la acción de cobro de la Administración tributaria, verifican la aplicación de esta norma en el tiempo y realizan un test de ponderación sobre los valores constitucionales en pugna.

PALABRAS CLAVE: prescripción; cobro de las deudas tributarias; seguridad jurídica; principio de igualdad; aplicación de normas en el tiempo.

Este trabajo es el resultado de un largo proceso de reflexión de los autores en el marco de una investigación que vienen realizando sobre ética y tributación. Algunas ideas aquí esbozadas provienen de la absolución de consultas que distintas empresas y la Administración tributaria pidieron a uno de los autores con ocasión del inicio de la vigencia de la Primera Disposición Complementaria del Decreto Legislativo 1421.

* Abogado. Magister en Derecho por la Pontificia Universidad Católica del Perú (PUCP). Profesor del Departamento de Derecho de la PUCP, Lima, Perú. Director de la revista Análisis Tributario. Contacto: Iduran@pucp.edu.pe

..* Bachiller en Derecho por la Pontificia Universidad Católica del Perú, Lima, Perú. Contacto: hugomarbieto@gmail.com

Nota del Editor: El presente artículo fue recibido por el Consejo Editorial de THËMIS-Revista de Derecho el 10 de enero de 2020, y aceptado por el mismo el 10 de marzo de 2020. 


\section{ANTECEDENTES}

Mediante el Decreto Legislativo 1113, vigente desde el 28 de setiembre del 2012, se incorporó como nuevo supuesto de inicio del plazo de prescripción para la acción de la Administración tributaria de exigir el pago de las deudas tributarias, a la notificación de las resoluciones de determinación o de multa, conforme al artículo 44:

\section{Cómputo de los plazos de prescripción:}

El término prescriptorio se computará:

[...]

7. Desde el día siguiente de realizada la notificación de las Resoluciones de Determinación o de Multa, tratándose de la acción de la Administración Tributaria para exigir el pago de la deuda contenida en ellas (2012).

Antes de esta modificación, el Código Tributario ${ }^{1}$ (en adelante, CT) establecía como una causal de interrupción a la notificación de una resolución de determinación (en adelante, RD) o de una resolución de multa (en adelante, RM), según se establecía en el inciso a del numeral 2 de su artículo 45. Conforme a ello, a partir de la notificación de la RD o de la RM se reiniciaba el cómputo del plazo de prescripción para exigir el cobro de la deuda tributaria notificada.

Con la publicación del Decreto Legislativo 1113 se derogó como causal de interrupción de la prescripción para exigir el cobro de la deuda a la notificación de la RD o $\mathrm{RM}^{2}$. A partir de dicha norma, este supuesto se entendía incluido dentro del artículo 44 como un nuevo inicio del plazo de prescripción.

Ahora bien, luego de incorporar como causal de inicio del cómputo de plazo de prescripción a la notificación de la deuda contenida en una RD o en una RM, surgió la duda sobre la aplicación en el tiempo de este nuevo supuesto. Es decir, respecto de la deuda tributaria cuyo plazo de prescripción hubiera empezado en un momento hasta el 1 de enero del 2012 y por la que se hubiera notificado una RD o una RM a partir del 28 de setiembre del 2012, correspondía dilucidar si el numeral 7 del artículo 44 del CT resultaba aplicable.

En el caso del nuevo numeral 7, no resultará aplicable el supuesto anterior. Así, ya habría prescrito el plazo de la Superintendencia Nacional de Aduanas y Administración Tributaria (en adelante, SUNAT) para cobrar la deuda en los casos señalados, pues ya se había derogado como causal de interrupción para exigir el cobro de la deuda al supuesto de la notificación de la RD o RM.

El Tribunal Fiscal (en adelante, TF), mediante la Resolución de observancia obligatoria 9789-4-2017, estableció el siguiente precedente vinculante administrativo sobre la materia en discusión:

El inicio del cómputo del plazo de prescripción de la acción de la Administración para exigir el pago de la deuda tributaria contenida en resoluciones de determinación y de multa emitidas por conceptos originados antes de la entrada en vigencia del Decreto Legislativo 1113, notificadas a partir del 28 de setiembre de 2012, se rigió por los numerales 1 a 4 del artículo 44 del Código Tributario, según correspondía, por lo que no resulta aplicable el numeral 7 del anotado artículo (2017).

Conforme se puede observar, el TF interpretó que no podía aplicarse el numeral 7 del artículo 44 del CT para la deuda cuyo plazo de prescripción empezó hasta el 1 de enero de 2012 porque ello supondría modificar el inicio del plazo de prescripción. Lo anterior implicaría aplicar de forma retroactiva lo establecido en el Decreto Legislativo 1113, interpretación que no sería válida conforme a la teoría de hechos cumplidos prevista en el artículo 103 de la Constitución Política del Perú.

En ese contexto se emitió el Decreto Legislativo 1421, publicado el 13 de setiembre del 2018, cuya primera disposición complementaria transitoria establece la siguiente regla:

\section{Cómputo del plazo de prescripción:}

Tratándose de procedimientos en trámite o pendientes de resolución el inicio del plazo prescriptorio para exigir el cobro de la deuda tributaria contenida en resoluciones de determinación o de multa cuyo plazo de prescripción de la acción para determinar la obligación tributaria o para aplicar sanciones se inició hasta el 1 de enero de 2012, notificadas a partir del 28 de setiembre de 2012 dentro del plazo de prescripción, se computa a partir del día siguiente de la notificación de tales resoluciones conforme con el numeral 7 del artículo 44 del Código Tributario (2018).

\footnotetext{
Debemos precisar que el Código Tributario se aprobó mediante el Decreto Legislativo 816, publicado el 21 de abril de 1996. Su actual Texto Único Ordenado fue aprobado por el Decreto Supremo 133-2013-EF, publicado el 22 de junio de 2013.

2 Cabe mencionar que este inciso fue modificado por el artículo 3 del Decreto Legislativo 1113. Luego de la modificación, este numeral indica que la causal de interrupción para exigir el pago de la obligación tributaria se interrumpe solo por la notificación de la orden de pago.
} 
La citada primera disposición complementaria transitoria del Decreto Legislativo 1421 (en adelante, PDCT) contradice el precedente vinculante emitido por el TF. Esta dispone que el numeral 7 del artículo 44 del CT sí resulta de aplicación para las deudas tributarias cuyo cómputo de plazo de prescripción inició hasta el 1 de enero de 2012.

Tras la evaluación de este aspecto, en las líneas que siguen procederemos a analizar si es válida la PDCT, a cuyos efectos evaluaremos los siguientes puntos: (i) la naturaleza de la institución de la prescripción y la cuestión tributaria; (ii) la prescripción de la acción de cobro por parte de la Administración tributaria; (iii) la naturaleza, retroactiva o no, del mandato de la PDCT; y, (iv) la constitucionalidad de la PDCT.

\section{LA NATURALEZA DE LA FIGURA DE LA PRES- CRIPCIÓN Y LA CUESTIÓN TRIBUTARIA}

\section{A. Sobre la definición de la prescripción ex- tintiva}

Antes de evaluar si prescribe la acción de cobro de la Administración tributaria en nuestro caso, corresponde entender a la figura de la prescripción. El tiempo constituye un hecho jurídico relevante que genera una modificación en las relaciones jurídicas de las personas (Vidal Ramírez, 2002, p. 12). La prescripción extintiva supone que, frente al inexorable paso del tiempo, la acción para hacer valer una pretensión se pierde porque no se ejercitó dentro de un plazo determinado.

Savigny indicó, en su obra Sistema del Derecho Romano Actual, que este tipo de prescripción no siempre se aplicó, pues fue durante largo tiempo desconocida. Ello quiere decir que esta institución jurídica no siempre estuvo presente en el devenir de la vida social de los seres humanos (1897, p. 200).

La justificación de la prescripción extintiva descansa, según Fernández Vidal, en la necesidad de otorgar seguridad jurídica a las relaciones jurídicas (2002, p. 106); en otras palabras, existe un interés público en el reconocimiento de la prescripción, ya que se buscaría evitar que las deudas sean eternamente exigibles, lo que haría imposible la vida social (Rubio Correa, 1987, p. 14). Si el titular del derecho no ejerce su pretensión dentro de un plazo razonable, el Estado -a través del órgano jurisdiccional- no se encontraría en la obligación de reconocer la pretensión del interesado.
En materia civil, el artículo 1989 del Código Civil establece que la prescripción extingue la acción, pero no el derecho mismo. Ello quiere decir que, en el supuesto de que el deudor cumpla con su obligación luego del vencimiento de su plazo de prescripción, el pago sería válido porque aún subsiste el derecho del acreedor a que le cumpla la obligación, por lo que el deudor no podría solicitar una devolución de lo pagado.

La figura de la prescripción también se encuentra establecida en materia penal. En líneas generales, el artículo 80 del Código Penal reconoce que la acción penal prescribe dentro de un plazo determinado por ley.

Conforme puede observarse, la figura de la prescripción formaría parte de un instituto fundamental en nuestro ordenamiento jurídico pues garantiza la seguridad jurídica. Procederemos a analizar esta figura dentro de la materia tributaria en el siguiente punto.

\section{B. La prescripción según el Código Tributario}

La prescripción no constituye un medio de extinción de la obligación tributaria, conforme se establece en el artículo 27 del CT. La prescripción en materia tributaria extingue la acción, pero no el derecho ${ }^{3}$, de conformidad con el tratamiento que le otorga el Código Civil a esta institución.

Si revisamos el artículo 43 del CT, podemos ver que existen varias prescripciones que delimitan en el tiempo la posibilidad de hacer valer las pretensiones de contenido tributario. Tales prescripciones son las siguientes:

La prescripción de la acción de la Administración [t]ributaria para la determinación de la obligación tributaria: La Administración [t]ributaria cuenta con un plazo para determinar la obligación tributaria del contribuyente. El plazo para la prescripción de la determinación de la obligación tributaria opera tanto cuando el deudor tributario presenta su declaración jurada como cuando esta no se realiza porque el deudor no se encontraba obligado o porque incumplió con su deber de colaboración. En doctrina se sostiene que, en realidad, la "prescripción de la acción para la determinación de la obligación tributaria" constituye un mecanismo de caducidad ${ }^{4}$.

3 En caso el deudor tributario realice el pago voluntario de su obligación tributaria prescrita, este no tiene el derecho a solicitar la devolución. En este caso, se observa que persiste el derecho del fisco a recibir el ingreso. Este tratamiento se reconoce expresamente en el artículo 49 del CT.

4 Hernández Berenguel argumenta que si se produce el vencimiento del plazo para la determinación de la obligación tributaria sin que dicha acción se ejerza, se extingue la acción y el derecho de la Administración tributaria para calcular la deuda (2006, pp. 445-446). 
La prescripción de la acción de la Administración [t]ributaria para exigir el pago de la deuda tributaria ${ }^{5}$ : Esta es la prescripción que se analiza en el presente artículo. Luego de que el deudor y la Administración [t]ributaria conocen que existe una deuda a favor del [f]isco, la Administración [t]ributaria solo puede cobrarla dentro de un lapso determinado. En caso no se realice el cobro en ese plazo, el deudor tributario puede oponer la prescripción para evitar el pago.

La prescripción de la acción de la Administración [t]ributaria para aplicar sanciones: El legislador incluyó en el Título I del Libro Cuarto del CT a las infracciones administrativas. En este título también se establecieron las sanciones por la comisión de esas infracciones. Si bien la Administración [t]ributaria cuenta con la facultad sancionadora, esta facultad para atribuir la comisión de infracciones a los administrados, sean deudores tributarios o no, debe realizarse dentro de un plazo de cuatro (4) años.

La prescripción de la acción de la persona, natural o jurídica, para solicitar o efectuar una compensación, así como para solicitar una devolución: Existe el derecho de los deudores tributarios a solicitar la devolución o compensar con las deudas tributarias no prescritas los pagos indebidos o en exceso ${ }^{6}$. La acción para solicitar o efectuar la compensación también prescribe a los cuatro (4) años (Hernández Berenguel, 2006, pp. 445-446).

La prescripción se regula en el Capítulo IV del Título III del Libro Primero del CT. Este capítulo tiene siete artículos (artículos 43 al 49). Cuando se realiza una interpretación sobre esta institución, no puede dejarse de lado la premisa relativa a que el conjunto normativo pretende ser suficiente y lógico.

\section{Valores constitucionales en disputa frente a la prescripción}

El Tribunal Constitucional peruano (en adelante, TC) se pronunció ${ }^{7}$ respecto a la naturaleza de la prescripción. Si bien analiza la prescripción desde el ámbito penal, los magistrados del Supremo Tribunal delimitaron la siguiente idea de esta institución vinculada a la seguridad jurídica:
Conforme a lo señalado por este Tribunal en reiterada jurisprudencia la prescripción, desde un punto de vista general, es la institución jurídica mediante la cual, por el transcurso del tiempo, la persona adquiere derechos o se libera de obligaciones.

Y, desde la óptica penal, es una causa de extinción de la responsabilidad criminal fundada en la acción del tiempo sobre los acontecimientos humanos o en la renuncia del Estado al ius punendi, bajo el supuesto de que el tiempo transcurrido borra los efectos de la infracción, existiendo apenas memoria social de ella. Dicho de otro modo, en una Norma Fundamental inspirada en el principio pro homine, la ley penal material otorga a la acción penal una función preventiva y resocializadora, en la cual el Estado autolimita su potestad punitiva; orientación que se funda en la necesidad de que, pasado cierto tiempo, se elimine toda incertidumbre jurídica y se abandone el castigo de quien lleva mucho tiempo viviendo honradamente, consagrando de esta manera el principio de seguridad jurídica (Expediente 2407-2011$\mathrm{PHC} / \mathrm{TC}, 2011$ ) [el énfasis es nuestro].

En líneas generales, el TC interpreta que en materia penal no se puede perseguir indefinidamente a quien vive "mucho tiempo honradamente" (2011), puesto que atentaría contra la seguridad jurídica. Si bien es cierto que su fundamento es la seguridad jurídica, asentimos con la postura de Vidal Ramírez cuando sostiene que mediante la aplicación de la prescripción extintiva se puede afectar la justicia o la equidad (2002, p. 106). Existe una vulneración a la idea de justicia, pues habrá situaciones en las que los deudores o delincuentes, pese a cometer una conducta no deseada por la sociedad, no se les podrá cobrar las deudas incumplidas ni sancionar a quienes cometieron delitos pues no se ejerció la acción dentro del plazo.

La vulneración al principio de equidad se manifiesta porque no todos los acreedores se verán satisfechos y algunos delincuentes podrán eximirse de la acción penal pese a que cometieron delitos. El argumento que se utiliza para sostener esta posición de injusticia, es que no puede perseguirse indefinidamente a los deudores o los delincuentes frente a la inactividad del deudor o del Estado en un plazo razonable.

De acuerdo al artículo 28 del CT, la deuda tributaria está constituida por el tributo, las multas y los intereses.

6 Debe tenerse en cuenta que el ordenamiento jurídico tributario también otorga el derecho a solicitar la devolución de importes que no califican como pagos indebidos o en exceso; por ejemplo, el ITAN.

7 Revisar el fundamento 2 de la Sentencia del Tribunal Constitucional (en adelante, STC) recaída en el Expediente 24072011-PHC/TC; numeral 2.3 de la STC recaída en el Expediente 02677-2014-PHC/TC; y el fundamento 3 de la STC recaída en el Expediente 01542-2015-PHC/TC. 


\section{D. ¿Debe existir la prescripción para la acción de cobro de la Administración tributaria?}

En el Derecho es claro que ninguna institución jurídica es neutral. Toda figura jurídica responde a intereses (concretos o abstractos) por parte de ciertos grupos sociales. No es posible naturalizar las figuras jurídicas como parte de un orden preestablecido o natural. El Derecho constituye un mecanismo de transformación social que permite modificar las instituciones que ya no respondan a las necesidades concretas de la sociedad.

Figuras como la propiedad individual, la herencia o la prescripción no son instituciones naturales para los seres humanos. De hecho, estas son establecidas por la sociedad dentro de un contexto político y económico concreto. Si ello es así, resulta válido y posible poner en cuestión la pertinencia de estas instituciones en el mundo actual ${ }^{8}$. Desde nuestra perspectiva, toda investigación debe partir por cuestionar los sentidos comunes que existen en la sociedad respecto a las instituciones jurídicas.

De este modo, resulta pertinente y necesario cuestionar la utilidad de la figura de la prescripción en el derecho. Conforme se señaló en el punto anterior, la idea de la prescripción responde a los deseos de la sociedad de privilegiar a la seguridad jurídica frente a la idea de justicia.

Hasta este punto, no es cierto que al día de hoy la prescripción sea una institución absoluta, puesto que hay delitos y obligaciones que son imprescriptibles. Debe analizarse si la justificación de la prescripción, en cada rama del derecho (civil, penal tributario, laboral), resulta suficiente para mantenerla en el futuro.

En materia penal, varios países de América Latina (Perú, Argentina, Bolivia, Chile, Colombia, Guatemala, México, Panamá y Paraguay) y Europa reconocen la imprescriptibilidad de los delitos de lesa. Conforme indica la Comisión Internacional de Juristas, la discusión sobre la imprescriptibilidad de estos delitos comenzó a gestarse en el seno de las Naciones Unidas y el Consejo de Europa ante el riesgo de que muchos responsables de crímenes de lesa humanidad cometidos durante la Segunda Guerra Mundial fueran beneficiados con la aplicación de las disposiciones sobre prescripción por parte de los tribunales nacionales humanidad (2014, pp. 385-386).

En el fondo, el delito de lesa humanidad constituye un crimen que merece un trato jurídico diferenciado por la gravedad excepcional que genera por la afectación a los derechos humanos como la vida y la dignidad. No se pueden olvidar estos delitos ni deben permanecer en la impunidad ${ }^{9}$ (Comisión internacional de juristas, 2014, p. 384).

Asimismo, en el Perú los delitos contra la Administración pública o el patrimonio del Estado son imprescriptibles en los supuestos más graves, conforme lo establece el artículo 41 de la Constitución Política vigente. Este supuesto debe entenderse dentro del contexto peruano, donde la corrupción de los funcionarios públicos genera un grave perjuicio pues el gasto público no se utiliza para solventar necesidades públicas. En ambos casos, existe una valoración superior del derecho a la verdad o la justicia frente al de la seguridad jurídica que podrían alegar los que cometieron crímenes de lesa humanidad o los delitos vinculados a la corrupción.

Ahora bien, no solo en materia penal opera la imprescriptibilidad. En materia pensionaria, la Ley $30425^{10}$ estableció la imprescriptibilidad de la acción de cobro de las Administradoras de Fondos de Pensiones (en adelante, AFP) por aportes previsionales. El fundamento de esta medida radica en que se tutela en este caso el derecho fundamental a la pensión frente al de la seguridad jurídica.

Esas evidencias permiten plantear que la prescripción no es una institución natural o absoluta y su prescindencia podría responder a la mayor importancia que pudiera tener un valor constitucional (equidad, verdad, derecho a la pensión) frente a la clásica idea de la seguridad jurídica. La valoración que se realiza sobre estos principios responde a las

8 No se pretende sostener, en este punto, que la idea de propiedad individual, herencia o la prescripción deba eliminarse sino empezar con la discusión sobre la necesidad o pertinencia de estas instituciones en el derecho, y más en el marco del proyecto del Estado Constitucional que lo sustenta.

$9 \quad$ El TC sostiene que

por la esencial ontología de los derechos humanos afectados por los crímenes de lesa humanidad, y las graves condiciones y circunstancias que caracterizan la realización de [e]stos, lleva a considerar que, en estos casos, la necesidad de la averiguación de la verdad, así como el procesamiento y posterior sanción de los responsables, constituye una norma de ius cogens, es decir, una norma imperativa de [d]erecho [i]nternacional susceptible de aplicarse erga omnes y que no admite pacto en contrario (Expediente 0024-2010-PI/TC, 2010).

10 Esta norma entró en vigencia el 21 de abril de 2016. 
creencias y actitudes de las sociedades dentro de los contextos particulares ${ }^{11}$.

Siendo ello así, ¿̇resulta pertinente aplicar la institución de la prescripción a la acción de cobro de las deudas tributarias? En este caso, existen dos valores que colisionan: por una parte, el deber que tiene el ciudadano de contribuir al sostenimiento del Estado para la consecución de los fines públicos ${ }^{12}$; en el otro extremo, los deudores tributarios tienen como una garantía fundamental, frente al Estado, la seguridad jurídica, que legitima la pérdida de la acción de la Administración tributaria para cobrar una deuda.

A la fecha, no existe un consenso en admitir que la acción de cobro de las deudas tributarias ya determinadas debe ser imprescriptible. La informalidad y la corrupción, en el caso peruano, dificultan la creación de una conciencia tributaria. Sin embargo, debe tenerse en cuenta que los recursos tributarios sirven para la construcción de un mejor país si se utilizan correctamente. En este sentido, la defensa de este interés público, cuyo fundamento constitucional sería el deber de contribuir, podría primar frente a la seguridad jurídica dentro de ciertos contextos sociales.

Si consideramos que la desigualdad en el mundo avanza, según investigaciones de la Organización de las Naciones Unidas ${ }^{13-14}$, ¿no sería una herramienta útil para el Estado, en su rol de lucha contra la desigualdad, la mayor recaudación que pueda generarse sobre deudas tributarias ya determinadas?

La prescripción beneficia a quien no cumple con sus obligaciones tributarias, pues quien no realizó el hecho imponible no tiene ni tendrá la obligación de realizar pago alguno. Siendo ello así, no pagar las deudas tributarias origina un perjuicio para toda la sociedad, ya que se prescinde de dinero que serviría para financiar las actividades estatales que potencialmente contribuyen al desarrollo del país.

No obstante, lo dicho, también debe reconocerse el importante rol que ha tomado el principio de seguridad jurídica en la construcción del Derecho moderno y, dentro de él, debemos reconocer que la noción de la prescripción ha servido de mucho para poner un punto fijo respecto a las disputas en cuanto a la asignación de derechos -especialmente de propiedad- y de obligaciones legales entre los ciudadanos.

En realidad, lo que hemos querido denotar en las líneas anteriores es que, en el derecho, sobre todo en el modelo del Estado Constitucional, las instituciones jurídicas y los principios fundamentales que les subyacen se recrean por una fina relación adecuada hacia el cumplimiento del valor justicia. Ello finalmente es puesto a prueba por los organismos que interactúan cotidianamente en la generación y aplicación del derecho. Entre todos ellos, los Tribunales Constitucionales tendrán siempre un rol privilegiado.

Más allá de lo que venimos indicando, continuaremos ahora con el análisis de la figura de la prescripción de la acción de cobro de la Administración tributaria para el caso en observación.

\section{LA PRESCRIPCIÓN DE LA ACCIÓN DE COBRO DE LA ADMINISTRACIÓN TRIBUTARIA}

\section{A. La determinación realizada por el contribu- yente y la verificación por parte de la Admi- nistración tributaria}

El artículo 59 del CT establece que la determinación de la obligación tributaria la puede realizar tanto el deudor tributario como la Administración tributaria, conforme al siguiente detalle:

\section{Determinación de la obligación tributaria:}

Por el acto de la determinación de la obligación tributaria:

a) El deudor tributario verifica la realización del hecho generador de la obligación tributaria, señala la base imponible y la cuantía del tributo.

b) La Administración [t]ributaria verifica la realización del hecho generador de la obligación tributaria, identifica al deudor tributario, señala la base imponible y la cuantía del tributo (Decreto Supremo 133, 2013).

11 El legislador, quien representa a la Nación, tiene la facultad de modificar las leyes dentro del procedimiento parlamentario. Luego, el Poder Judicial o el TC pueden analizar la constitucionalidad de las normas en los procesos de amparo o inconstitucionalidad. En todos estos casos, existirá una valoración de los magistrados o los legisladores sobre qué principio debe prevalecer para cada caso concreto.

12 En ese sentido, véase la STC recaída en el Expediente 0004-2004-AI/TC.

13 Sugerimos revisar Organización de las Naciones Unidas (2019, p. 87). Resulta relevante empezar a discutir cuáles son las medidas que deben contribuir a la lucha contra la desigualdad.

14 En este informe, la ONU aclara que el "dogma" de que la creación de riqueza necesariamente repercute para todos ha sido ampliamente refutado (2019, p. 87). 
En ese sentido, de una interpretación sistemática en relación con los artículos $60^{15}$ y $61^{16}$ del CT, podemos establecer que los deudores tributarios tienen el deber de liquidar la deuda tributaria (verificar la realización del hecho generador de la obligación tributaria, señalar la base imponible y la cuantía del tributo).

Asimismo, la Administración tributaria tiene la facultad de modificar la determinación de la obligación tributaria realizada por el contribuyente. Nótese que esta facultad implica que la Administración tributaria puede determinar una mayor deuda a la declarada por el contribuyente. Esta diferenciación puede confirmarse de la lectura del artículo $63^{17}$ del CT. La Administración tributaria, durante el periodo de prescripción, puede determinar la obligación tributaria sobre base cierta o sobre base presunta.

Por otra parte, el inciso a del artículo $115^{18}$ del CT establece que las deudas establecidas mediante RD o RM serán exigibles coactivamente cuando no sean reclamadas dentro del plazo de ley. En otras palabras, este inciso regula el momento a partir del cual pueden cobrarse las deudas tributarias determinadas por la Administración tributaria.

Resulta lógico que la cobranza de las deudas determinadas por la SUNAT recién se produzca luego de notificada la RD y de la fecha de vencimiento del plazo legal para interponer el recurso de reclamación. Antes de la notificación de este acto administrativo, no habría una deuda que pagar en el supuesto de que el contribuyente haya cancelado previamente su obligación tributaria autoliquidada.

Por lo tanto, a partir de una interpretación sistemática de estos artículos, podemos concluir que, en términos generales, los tributos son determinados por los deudores tributarios. Luego, esa determinación puede ser modificada por la Administración tributaria. Si ello es así, existiría un importe omitido, en caso el fisco determine un mayor tributo, que el contribuyente debe regularizar.

Esta situación permite plantear la siguiente cuestión: Si la SUNAT establece que el contribuyente determinó incorrectamente el tributo, por lo que existe una deuda con el fisco, ¿dicha Administración tributaria no debería tener un plazo razonable para poder cobrar esa deuda que el contribuyente no incluyó en su declaración jurada?

\section{B. Sobre la figura de la prescripción y el Código Tributario}

EI CT diferencia entre la acción para: (i) determinar la obligación tributaria; (ii) exigir su pago; y, (iii) aplicar sanciones. En todos estos casos, la acción prescribe a los cuatro (4) años. El artículo 44 del CT establece el inicio del cómputo del plazo de prescripción para las acciones señaladas en el párrafo anterior.

Desde una aplicación literal de la norma, el inicio del plazo de prescripción para cobrar la deuda, antes de la modificación legislativa realizada

15 Conforme expresa textualmente el artículo 60 del CT: Inicio de la determinación de la obligación tributaria La determinación de la obligación tributaria se inicia: 1. Por acto o declaración del deudor tributario.

2. Por la Administración Tributaria; por propia iniciativa o denuncia de terceros.

Para tal efecto, cualquier persona puede denunciar a la Administración Tributaria la realización de un hecho generador de obligaciones tributarias (Decreto Supremo 133, 2013).

16 Conforme expresa textualmente el artículo 61 del CT:

Fiscalización o verificación de la obligación tributaria efectuada por el deudor tributario

La determinación de la obligación tributaria efectuada por el deudor tributario está sujeta a fiscalización o verificación por la Administración Tributaria, la que podrá modificarla cuando constate la omisión o inexactitud en la información proporcionada, emitiendo la Resolución de Determinación, Orden de Pago o Resolución de Multa (Decreto Supremo 133, 2013).

17 Conforme expresa textualmente el artículo 63 del CT:

Determinación de la obligación tributaria sobre base cierta y presunta

Durante el período de prescripción, la Administración Tributaria podrá determinar la obligación tributaria considerando las bases siguientes:

1. Base cierta: tomando en cuenta los elementos existentes que permitan conocer en forma directa el hecho generador de la obligación tributaria y la cuantía de la misma.

2. Base presunta: en mérito a los hechos y circunstancias que, por relación normal con el hecho generador de la obligación tributaria, permitan establecer la existencia y cuantía de la obligación (Decreto Supremo 133, 2013).

18 Conforme expresa textualmente el artículo 115 del CT:

Deuda exigible en cobranza coactiva

La deuda exigible dará lugar a las acciones de coerción para su cobranza. A este fin se considera deuda exigible: a) La establecida mediante Resolución de Determinación o de Multa o la contenida en la Resolución de pérdida del fraccionamiento notificadas por la Administración y no reclamadas en el plazo de ley. En el supuesto de la resolución de pérdida de fraccionamiento se mantendrá la condición de deuda exigible si efectuándose la reclamación dentro del plazo, no se continúa con el pago de las cuotas de fraccionamiento (Decreto Supremo 133, 2013). 
mediante el Decreto Legislativo 1113, empezaba en la misma oportunidad que el plazo para determinar la deuda porque la norma no habría hecho una diferencia entre ambos plazos. Por lo tanto, bajo ese entendimiento, cuando la norma se modificó eliminándose como causal de interrupción a la notificación de la RD y más bien se la estableció como un nuevo inicio del plazo de prescripción, la SUNAT ya no podía cobrar esas deudas porque no era válido modificar el inicio del plazo de prescripción y ya no existía causal de interrupción. Conforme a esta interpretación, se genera como consecuencia que la RD no tenga efectos para algunos contribuyentes. Este es el criterio que maneja el $\mathrm{TF}$, el cual consideramos incorrecto.

Sin embargo, no puede interpretarse aisladamente el artículo 44 del CT sin analizar las causales de interrupción. EI CT siempre reguló dos plazos distintos para exigir el cobro de las deudas tributarias. Esto dependía de quien realizaba la determinación.

De hecho, antes de la vigencia del Decreto Legislativo 1113, el artículo 44 del CT establecía las siguientes reglas:

\section{Cómputo de los plazos de prescripción} El término prescriptorio se computará:

1. Desde el uno (1) de enero del año siguiente a la fecha en que vence el plazo para la presentación de la declaración anual respectiva.

2. Desde el uno (1) de enero siguiente a la fecha en que la obligación sea exigible, respecto de tributos que deban ser determinados por el deudor tributario no comprendidos en el inciso anterior.

3. Desde el uno (1) de enero siguiente a la fecha de nacimiento de la obligación tributaria, en los casos de tributos no comprendidos en los incisos anteriores.

4. Desde el uno (1) de enero siguiente a la fecha en que se cometió la infracción o, cuando no sea posible establecerla, a la fecha en que la Administración Tributaria detectó la infracción.

5. Desde el uno (1) de enero siguiente a la fecha en que se efectuó el pago indebido o en exceso o en que devino en tal, tratándose de la acción a que se refiere el último párrafo del artículo anterior.

6. Desde el uno (1) de enero siguiente a la fecha en que nace el crédito por tributos cuya devolución se tiene derecho a solicitar, tratándose de las originadas por conceptos distintos a los pagos en exceso o indebidos (Decreto Supremo 133, 2013).
Asimismo, el inciso a) del numeral 2 del artículo 45 del CT incluía la siguiente causal de interrupción:

\section{Interrupción de la prescripción}

[...]

2. El plazo de prescripción de la acción para exigir el pago de la obligación tributaria se interrumpe:

a) Por la notificación de la orden de pago, resolución de determinación o resolución de multa (Decreto Supremo 133, 2013).

Desde una interpretación literal, podríamos asumir que solo existía un plazo de prescripción para exigir el cobro de la deuda tributaria pues, a partir de una revisión de los supuestos del artículo 44 del CT, el numeral 1 de este artículo indica expresamente que el plazo de prescripción solo se origina al año siguiente de la presentación de la declaración jurada. Sin embargo, esta no resultaría coherente si se pretende entender a la prescripción como una institución en el CT. Antes de la modificación legislativa, existía un plazo de prescripción para cobrar la deuda declarada por el contribuyente y otro para cobrar la deuda determinada por la Administración Tributaria.

\section{Deuda declarada por el contribuyente}

Resulta razonable que la SUNAT tenga un plazo de cuatro (4) años desde el ejercicio siguiente al de la presentación de la declaración jurada para exigir el cobro de la deuda declarada. Efectivamente, solo puede iniciarse el plazo de prescripción de la acción de cobro de la deuda tributaria que el contribuyente comunicó mediante su declaración jurada. Por otra parte, antes de la notificación de una resolución de multa, al administrado no se le puede exigir coactivamente el pago de la multa, pues aún no se le notificaba el acto administrativo correspondiente.

\section{Deuda declarada por la Administración tri-} butaria

Conforme podemos observar en el punto anterior, la notificación de la RD permitía que el deudor tributario conozca la liquidación del impuesto que realizaba la Administración tributaria. A partir de ese momento, se reiniciaba el plazo de prescripción que tenía la Administración para cobrar la deuda contenida en la RD o RM.

En esa línea, no resultaba lógico que se inicie el plazo de prescripción para exigir el cobro de la deuda determinada por la SUNAT antes de que se notifique la RD o RM. Solo a partir de ese momento el deudor conocía que tenía una deuda que el Fisco podía cobrar. No puede computarse el plazo 
de prescripción para el cobro de la deuda si todavía no se puede accionar. Esto solo ocurre cuando se notifica la RD o RM. Por esta razón, no es cierto que el CT estableció que sea lo mismo el plazo para la prescripción de la acción a fin de exigir el cobro de la deuda determinada por la SUNAT y el plazo para la prescripción de la acción para exigir el cobro de la deuda declarada por el contribuyente.

El CT siempre incluyó como causal de interrupción a la notificación de la RD o RM. Nuestro primer CT, aprobado mediante el Decreto Supremo $263-\mathrm{H}$ el 12 de agosto de 1966, estableció que la notificación de la acotación del tributo generaba la interrupción de la prescripción de la deuda tributaria (es decir, el cómputo de un nuevo plazo), conforme se indica a continuación:

\section{Artículo 41.-}

La prescripción se interrumpe:

Por la notificación de acotación del tributo [...] El nuevo término prescriptorio se computará desde el día siguiente al acaecimiento del acto interruptorio [...] (Decreto Supremo 263, 1966).

Observamos que a partir de la notificación de "acotación del tributo" (Decreto Supremo 263, 1966), la Administración tributaria contaba con un nuevo plazo de prescripción para cobrar la deuda tributaria determinada por ella misma.

Cabe señalar que el inicio del plazo para exigir el cobro de la deuda determinada por la Administración tributaria se encuentra concatenado con el plazo que tiene la SUNAT para determinar la deuda. La notificación de la RD debe realizarse dentro del plazo de prescripción para la determinación de la deuda. Una vez que se notifica, empieza a correr el plazo de prescripción para que la SUNAT pueda cobrar la deuda contenida en ella.

Por estas razones, desde una interpretación sistemática ${ }^{19}$, consideramos que el CT siempre reguló dos plazos distintos para exigir el cobro de las deudas tributarias. Reiteramos, un primer plazo de prescripción empezaría desde el 1 de enero del año siguiente de la fecha de presentación de la declaración jurada. Este sería el plazo de prescripción para exigir el cobro de la deuda declarada por el contribuyente. Además, este mismo plazo de prescripción sería el que tiene el fisco para verificar la determinación realizada por el contribuyente.

El segundo plazo de prescripción sería aquel para exigir el cobro de la deuda determinada por la
SUNAT, que empezaba a correr luego de la notificación de la RD o RM. Si bien este plazo no se encontraba expresamente regulado en el artículo 44 del CT, ello debía deducirse de una interpretación sistemática de lo dispuesto en todos los artículos del CT sobre prescripción, concretamente en los artículos 59, 60 y 61, y en el inciso a) del artículo 115 del CT.

Resulta relevante citar al profesor uruguayo Valdés Costa, quien fue uno de los encargados de la elaboración del Modelo de CT para América Latina. En su obra, este autor vierte sus reflexiones sobre la necesidad de establecer un plazo especial de prescripción para realizar el cobro de las deudas determinadas por la Administración tributaria:

Otro aspecto tratado por la doctrina y con repercusión en ciertos derechos es la distinción entre prescripción para adoptar el acto de determinación a partir del acaecimiento del hecho generador y otro para hacer el cobro a partir del acto de determinación. Al establecer el efecto interruptivo del acto de determinación, el problema queda solucionado en favor del doble plazo (2013, pp. 415-416) [el énfasis es nuestro].

Nótese que este autor concuerda con nuestra posición al interpretar que existen dos plazos de prescripción distintos para el cobro de la deuda: uno para el cobro de la deuda determinada por el contribuyente y otro para el cobro de la deuda determinada por la Administración tributaria.

En esencia, más allá de ser una causal de interrupción, se evidencia que existía un nuevo plazo de prescripción. Este nuevo plazo se origina porque a partir de la notificación de la RD el contribuyente sabe que tiene una deuda con el fisco, por lo que recién desde ese momento puede empezar el plazo de prescripción para el cobro de la deuda determinada por la Administración tributaria.

\section{IV. ¿TIENE CARÁCTER RETROACTIVO LA DE- MANDA DE LA PDCT?}

\section{A. Posición del Tribunal Fiscal}

En la Resolución del Tribunal Fiscal (en adelante, RTF) 09789-4-2017, el TF considera que no puede aplicarse el numeral 7 del artículo 44 del CT para las deudas cuyo plazo de prescripción comenzó en algún momento hasta el 1 de enero de 2012 y por las que la SUNAT notificó resoluciones de

19 Rubio Correa y Arce Ortiz sostienen que el "método sistemático por comparación de normas interpreta una norma atribuyéndole los principios o conceptos que quedan claros en otras normas de su mismo conjunto normativo pero que no quedan claramente expresados en ella" (2017, p. 115). 
determinación o multa a partir del 28 de setiembre del 2012, porque modificar el inicio del cómputo del plazo genera una aplicación retroactiva de la norma. Los fundamentos que sustentan la posición del TF, específicamente en las páginas seis y siete del Acta de Reunión de Sala Plena 2017-17, son los siguientes:

Todo plazo tendría tres requisitos esenciales: inicio, término y cuerpo del plazo.

Respecto al momento de inicio de plazo de prescripción, este se agota con su mera producción, por lo que la norma aplicable al anotado hecho es la que se encontraba vigente en el momento de su producción.

Mientras se computa el plazo de prescripción y la norma que establece el inicio del plazo se modifica, no puede aplicarse la norma posterior porque el inicio del plazo de prescripción ya es un "hecho cumplido". Utilizar la norma posterior para ver el "inicio" supone aplicarla retroactivamente (2017).

Sin embargo, debe tomarse en cuenta que en la RTF 7441-1-201920, el TF se pronunció sobre el criterio de observancia obligatoria establecido en la RTF 09789-4-2017 y a la aplicación de lo dispuesto en la PDCT. En efecto, entre los fundamentos que esgrime el TF, se señala que los fundamentos de la última resolución citada no resultan pertinentes al caso pues se aplica expresamente la citada PDCT y que no tiene competencia para evaluar la inconstitucionalidad de esta norma conforme se ha establecido en la STC 4293-2012-PA/TC.

\section{B. ¿Existe una vulneración a la teoría de los hechos cumplidos?}

El artículo 103 de la Constitución Política del Perú ordena que "la ley, desde su entrada en vigencia, se aplica a las consecuencias de las relaciones y situaciones jurídicas existentes y no tiene fuerza ni efectos retroactivos; salvo, en ambos supuestos, en materia penal cuando favorece al reo [...]" (Const., 1993, art. 103). A través de este artículo, el constituyente estableció que toda norma se aplica por los hechos que suceden mientras tenga vigencia. En ese sentido, "si se genera un derecho bajo una primera ley y luego de producir ciertos efectos esa ley se modifica por una segunda, a partir de la vigencia de esta nueva ley los nuevos efectos del derecho deben adecuarse a este y ya no ser regidos por la norma anterior" (Rubio Correa, 2013, p. 29).

Por otra parte, la aplicación retroactiva implica que una norma producirá efectos jurídicos por hechos generados antes de que entre en vigencia la primera norma. La aplicación retroactiva solo se encuentra permitida en materia penal cuando favorece al reo $^{21}$. A efectos de verificar si existe una aplicación retroactiva, conviene determinar cuál es el hecho relevante y en qué momento se produce.

Conforme señalamos en el punto anterior, el plazo de prescripción para el cobro de la deuda tributaria por parte de la Administración tributaria se refiere a dos supuestos: (i) el plazo para exigir el cobro de la deuda declarada por el contribuyente; y, (ii) el plazo para exigir el cobro de la deuda determinada por la SUNAT. En el caso concreto, el hecho relevante es la notificación de la RD o la RM que realiza la Administración tributaria. Este es el hecho (su origen) que genera el inicio del cómputo del plazo de prescripción para cobrar la deuda contenida en el documento notificado. En buena cuenta, a partir de esa notificación el deudor tributario sabe que la SUNAT le imputa una deuda que deberá pagar.

El ámbito de aplicación de la PDCT precisa que se incluye solo a las notificaciones de RD o RM realizadas desde el 28 de setiembre del 2012. Por lo tanto, el hecho relevante, esto es la notificación de la RD o la RM, se produce después de la entrada en vigencia del Decreto Legislativo 1113. No existe una aplicación retroactiva porque el origen del hecho relevante (notificación de las resoluciones) no se produce antes del 28 de setiembre del 2012. En estricto, hablamos de un hecho que se produce después de la entrada en vigencia de la norma.

La PDCT no modifica el plazo de prescripción para determinar la deuda o exigir el pago de la deuda declarada por el contribuyente. Sin perjuicio de este aspecto, la prescripción, como hecho relevante, solo se puede entender como ganada cuando culmine el plazo de prescripción, lo que no sucedía en el caso de autos. Si una norma modifica el plazo de prescripción para determinar o cobrar la deuda declarada por el contribuyente cuyo plazo de prescripción aún no culminaba, resulta válida la modificación del plazo porque todavía no se ganaba la prescripción.

\footnotetext{
20 Que tiene carácter de observancia obligatoria en cuanto a que "[l]a sola interposición de una acción de amparo no suspende la aplicación de una norma o la ejecución de un acto administrativo puesto que para ello se requiere de una medida cautelar firme que suspenda los efectos de las normas o de los actos administrativos, según sea el caso, contra los cuales se ha recurrido en vía de amparo" (2019).

21 Véase la Constitución Política del Perú [Const.] (1993) Artículo 103.
} 
Debe precisarse que el hecho relevante tiene un significado distinto al hecho cumplido. En la prescripción, el hecho relevante alude al momento en el que empieza a formarse la situación jurídica (pero aún no termina de configurarse la nueva situación jurídica); mientras que el hecho cumplido, en materia de prescripción, solo puede entenderse cuando se cumpla el plazo de prescripción sin la acción de la Administración tributaria. En ese momento se entiende que se gana la prescripción.

Por estas razones, la PDCT no establece una aplicación retroactiva del Decreto Legislativo 1113. Concluimos que, de conformidad con el artículo 103 de la Constitución Política del Perú, es válida la PDCT, pues aplica la teoría de los hechos cumplidos al caso concreto.

\section{Posición de la jurisprudencia}

Existen, en este aspecto, dos antecedentes en la vía judicial sobre la materia en controversia. Estos son (i) la incorporación de una causal de interrupción para el plazo de prescripción de determinación de la deuda tributaria; y, (ii) la diferencia entre el plazo para aplicar sanciones y el plazo de prescripción para cobrar la deuda de una resolución de multa y la teoría de los hechos cumplidos.

Con respecto al primer antecedente, la Corte Suprema, mediante la Sentencia de Casación 8312 2015 , considera que mientras no culmine el plazo de prescripción para determinar la deuda por parte de la Administración tributaria, en virtud de la teoría de los hechos cumplidos, una norma cuya entrada en vigencia se produjo antes de que culmine el plazo de prescripción antes referido puede introducir una nueva causal de interrupción del plazo de prescripción para determinar la deuda. Esta nueva causal no se encontraba prevista en el momento en el que se originó el inicio del cómputo del plazo de prescripción. Esta posición no es similar al caso materia de discusión, pero resulta relevante para entender que la prescripción solo se gana cuando culmina el plazo correspondiente.

Con respecto al segundo antecedente, la Sétima Sala de la Corte Superior de Justicia de Lima, mediante la Resolución 19, emite la sentencia que resuelve el Expediente 07461-2015-0-1801-JRCA-20. En un caso similar al de la actual discusión, considera que la incorporación del supuesto de inicio del plazo de prescripción del numeral 7 del artículo 44 del CT (en este caso, del plazo para el cobro de una multa notificada en una RM) es un supuesto distinto al inicio del plazo de prescripción para aplicar la sanción de multa, regulado en el numeral 4 del artículo 44 del CT.
Por lo tanto, la RM notificada al amparo del numeral 4 del artículo 44 del CT -notificada después del 28 de setiembre del 2012- por una infracción cuyo plazo de prescripción para aplicar la sanción no prescribía al momento de la notificación, sí generaba el inicio de un nuevo plazo para cobrar la deuda notificada en la resolución de multa. En buena cuenta, la Sala sostiene que la aplicación del numeral 7 del artículo 44 del CT no es retroactiva para ese caso, sino que respondería a la teoría del hecho cumplido.

Si bien en este caso la Corte Superior diferencia entre la acción para aplicar la sanción y la acción para cobrar la multa, no existe una argumentación suficiente que explique por qué en este caso no hay una aplicación retroactiva. Sin embargo, este precedente demuestra que la judicatura tiene una posición similar a la expuesta.

\section{D. ¿La PDCT es una norma interpretativa o in- novativa?}

Resulta necesario dilucidar si la PDCT es una norma interpretativa o innovativa. En caso sea una norma innovativa, ella solo producirá efectos luego de su entrada en vigencia. En cambio, si la norma es interpretativa, esta debe regir desde la entrada en vigencia de la norma interpretada.

Ahora bien, de acuerdo a lo desarrollado en el fundamento 20 de la STC 002-2006-PI/TC “las normas interpretativas son aquellas que declaran o fijan el sentido de una norma dictada con anterioridad y se reconocen porque, al promulgarlas el legislador, generalmente utiliza palabras como interprétese, aclárese o precísese" (2006). La finalidad de toda norma interpretativa, según el TC, es "eliminar la ambigüedad que produce en el ordenamiento jurídico. Así, ambas normas - la interpretada y la interpretativa - están referidas a la misma" (Expediente 002-2006-PI/TC, 2006).

La PDCT no precisa una interpretación sobre el contenido del texto previsto en el numeral 7 del artículo 44 del CT, sino que analiza cómo debe aplicarse en el tiempo esta norma. Además, la PDCT se origina ante la incertidumbre sobre la aplicación de la regla del citado numeral 7 del artículo 44; puesto que existía confusión respecto a esta norma y si debía aplicarse para las deudas cuyo plazo de prescripción aún no terminaba de computarse cuando entró en vigencia el Decreto Legislativo 1113.

Cuando una norma interpretativa busca fijar un sentido, debe entenderse que también se refiere a la forma en la que debe aplicarse en el tiempo esta norma. En estos casos, también pueden existir varias posiciones sobre la forma en la que debe 
aplicarse la norma en el tiempo ${ }^{22}$. En realidad, la PCDT del Decreto Legislativo 1421 solo precisa que, de acuerdo al artículo 103 de la Constitución Política, se aplica al caso concreto la teoría de los hechos cumplidos.

Por esta razón, consideramos que la PDCT es una norma interpretativa. Resulta oportuno indicar que generalmente este tipo de normas utiliza palabras como aclárese o precísese. No obstante, el uso de estas palabras no constituye una condición para que una norma sea interpretativa.

La jurisprudencia del $\mathrm{TC}^{23}$ desarrolló los requisitos para conocer la existencia de una norma interpretativa, los cuales procedemos a explicar.

- "Primero, debe referirse expresamente a una norma legal anterior" (Expediente 0022006-PI/TC, 2006).

Sobre este punto, nótese que la PDCT no remite literalmente al Decreto Legislativo 1113. Sin embargo, sí se hace mención a la norma en conflicto, es decir, al numeral 7 del artículo 44 del CT. Este numeral fue incorporado mediante el Decreto Legislativo 1113. Al día de hoy, no hay ninguna modificación con respecto a este numeral.

- "Segundo, debe fijar el sentido de dicha norma anterior enunciando uno de los múltiples significados plausibles de la norma interpretada, el cual pasa, por decisión del propio legislador, a ser el significado auténtico que excluye las demás interpretaciones de la norma anterior" (Expediente 002-2006-PI/TC, 2006).

Existen múltiples posiciones sobre la aplicación en el tiempo de la norma interpretada (numeral 7 del artículo 44 del CT). Esto se evidencia cuando el TF tuvo que emitir un precedente de observancia obligatoria para fijar una posición sobre el tema.

Por una parte, se interpreta que es retroactiva la aplicación del numeral 7 del artículo 44 del CT para las deudas cuyo plazo de prescripción se iniciaron antes de la entrada en vigencia de la norma, el 28 de setiembre del 2012.
La otra posición sostiene que la aplicación del numeral 7 del artículo 44 del CT para las deudas cuyo cómputo de plazo de prescripción se iniciaron antes de la entrada en vigencia del Decreto Legislativo 1113 es válida pues responde a la teoría de los hechos cumplidos. Por lo tanto, no habría aplicación retroactiva. El legislador, a través de la PDCT, precisa como significado a la segunda interpretación de las que mencionamos. Esta interpretación sería el significado auténtico.

- $\quad$ "Tercero, no debe agregarle a la norma interpretada un contenido que no estuviera comprendido dentro de su ámbito material" (Expediente 002-2006-PI/TC, 2006).

Dentro del ámbito de posibles significados de la PDCT, visto conjuntamente con el artículo 103 de la Constitución Política, consideramos que el contenido regulado en esa norma es la única opción válida porque es una interpretación del mandato constitucional de los hechos cumplidos al caso concreto.

La primera posición comentada líneas arriba supondría establecer que las reglas sobre una prescripción no ganada, previas a la entrada en vigencia del Decreto Legislativo 1113 , serían derechos adquiridos inmodificables, lo cual sería inconstitucional.

Por estas razones, la PDCT es una norma interpretativa. El numeral 7 del artículo 44 del CT (norma interpretada), incorporada al ordenamiento jurídico mediante el Decreto Legislativo 1113, debe interpretarse en concordancia con la norma interpretativa.

V. EN EL SUPUESTO DE QUE LA PDCT ESTABLECIERA UNA APLICACIÓN RETROACTIVA DEL NUMERAL 7 DEL ARTÍCULO 44 DEL CÓDIGO TRIBUTARIO ¿SERÍA CONSTITUCIONAL LA PDCT?

\section{A. Defensa del principio de igualdad en mate- ria tributaria}

Si se asume que la PDCT ordena una aplicación retroactiva del numeral 7 del artículo 44 del CT, no aplicar la PDCT genera la afectación del principio

22 En este punto, debemos indicar que la jurisprudencia del TC aún no desarrolla la idea de una norma interpretativa en la que se precise la aplicación en el tiempo de una norma anterior. Este caso sería un supuesto atípico; sin embargo, no modifica una norma jurídica anterior porque se limita a aplicar la teoría de los hechos cumplidos.

23 Véase el fundamento 23 de la STC recaída en el Expediente 002-2006-PI/TC. En realidad, estos requisitos habían sido ya desarrollados por la Corte Constitucional de Colombia. 
de igualdad en materia tributaria. De acuerdo al TC, el principio de igualdad busca establecer que, en iguales circunstancias de hecho, no debe legislarse de forma tal que se generen consecuencias de desigualdad en el trato impositivo (Expediente 1157-98-AA/TC, 1998).

El objetivo de la PDCT es evitar que se genere un privilegio indebido para un reducido grupo de contribuyentes. No hay una justificación válida para que las notificaciones de las RD o RM a estos deudores tributarios no deban surtir efectos.

Este grupo de deudores tributarios evidenció su capacidad contributiva para el pago de impuestos, pues realizaron actividades económicas que exteriorizaban riquezas susceptibles de ser gravadas. No sería legítimo establecer un beneficio tributario para este grupo, sin un motivo válido, frente a los otros deudores.

Por estas razones, la PDCT encuentra como fundamento constitucional el principio de igualdad en materia tributaria. En caso no se aplique esta nor$\mathrm{ma}$, se genera un privilegio indebido y no deseado para un grupo de deudores tributarios.

\section{B. ¿Existe una vulneración al principio de pro- hibición de abuso del derecho?}

El Congreso de la República, a través del grupo de trabajo encargado del Control Constitucional de Actos Normativos del Poder Ejecutivo, mediante el Informe 90/2018-2019 respecto al Decreto Legislativo 1421, considera que la PDCT tiene como fundamento constitucional el principio de prohibición de abuso del derecho (2019, pp. 20-21). Este principio $^{24}$ busca evitar que las personas, mediante conductas fraudulentas o malintencionadas, pretendan conseguir un derecho de forma ilegítima o abusiva.
En este caso, no resulta de aplicación este principio. No existe una conducta fraudulenta o negligente de los deudores tributarios que origine la obtención de un beneficio indebido. El conflicto se origina por la aplicación de una norma (numeral 7 del artículo 44 del CT) en el tiempo.

Los conflictos sobre aplicación de las normas en el tiempo no suponen el ejercicio abusivo de un derecho. No se discuten las conductas de los deudores tributarios ni los hechos del caso. La respuesta a este problema debe partir de un estricto análisis jurídico.

\section{Afectación al principio de seguridad jurídica}

El principio de seguridad jurídica ${ }^{25}$ busca que los ciudadanos sepan razonablemente cómo actuará el Estado. Este principio otorga predictibilidad al ordenamiento jurídico. La teoría de los hechos cumplidos y la regulación de la prescripción encuentran su justificación en la seguridad jurídica.

La aplicación de la teoría de los hechos cumplidos sirve para que la ciudadanía sepa desde cuándo y cuáles serán los efectos de la incorporación de una norma en el ordenamiento jurídico. En cambio, la prescripción se vincula con la seguridad jurídica porque este mecanismo evita que exista una persecución indefinida contra los deudores tributarios. Esta figura otorga estabilidad a las relaciones jurídicas de los deudores tributarios frente a la inactividad del Estado.

Si asumimos que la PDCT contiene un mandato retroactivo, habría una modificación de las reglas sobre la prescripción sin respetar el mandato constitucional de no cambiar las consecuencias generadas antes de la vigencia de la nueva norma. Por lo tanto, en ese supuesto, prima facie, la PDCT podría ser inconstitucional por afectar al principio de

24 Como ha señalado el Tribunal Constitucional en su jurisprudencia:

Sobre el particular, debe recordar este Tribunal que la cláusula constitucional que proscribe el abuso del derecho, aplicada al ámbito de los derechos fundamentales, supone la prohibición de desnaturalizar las finalidades u objetivos que sustentan la existencia de cada atributo, facultad o libertad reconocida sobre las personas. Los derechos, pues, no pueden utilizarse de una forma ilegítima o abusiva, como ocurre en el presente caso, en que la empresa Telefónica S.A.A. pretenda obtener un doble beneficio por una misma causa, lo que a todas luces resulta inconstitucional (Expediente 05296-2007-PA/TC, 2007; Expediente 00037-2012-PA/TC, 2012).

25 Según el Tribunal Constitucional:

El principio de la seguridad jurídica forma parte consubstancial del Estado Constitucional de Derecho. La predictibilidad de las conductas (en especial, las de los poderes públicos) frente a los supuestos previamente determinados por el Derecho, es la garantía que informa a todo el ordenamiento jurídico y que consolida la interdicción de la arbitrariedad. Tal como estableciera el Tribunal Constitucional español, la seguridad jurídica supone "la expectativa razonablemente fundada del ciudadano en cuál ha de ser la actuación del poder en aplicación del Derecho" (STCE $36 / 1991$, FJ 5). El principio in comento no sólo supone la absoluta pasividad de los poderes públicos, en tanto no se presenten los supuestos legales que les permitan incidir en la realidad jurídica de los ciudadanos, sino que exige de ellos la inmediata intervención ante las ilegales perturbaciones de las situaciones jurídicas, mediante la "predecible" reacción, sea para garantizar la permanencia del statu qua, porque así el Derecho lo tenía preestablecido, o, en su caso, para dar lugar a las debidas modificaciones, si tal fue el sentido de la previsión legal (Expediente 0016-2002$\mathrm{Al} / \mathrm{TC}, 2002)$. 
seguridad jurídica, pero aún debemos proceder a aplicar el test de ponderación constitucional.

\section{Aplicación del test de ponderación}

Los derechos y principios reconocidos en la Constitución Política no son absolutos. Si ello es así, debe existir un método jurídico que permita resolver el conflicto de principios cuando colisionen en un caso concreto, ya que los clásicos mecanismos de solución de controversias jurídicas se crearon para resolver problemas de reglas y no de principios.

El test de ponderación se aplica cuando colisionan principios. De acuerdo a Durán Rojo, "ponderar acaba siendo una consideración imparcial de los aspectos contrapuestos de dos o más principios, de modo que uno de ellos prima sobre el otro en un caso concreto, aunque abstractamente en principio permanecen iguales" (2004, p. 13).

El test de ponderación, en otras palabras, se aplica para resolver un problema jurídico en el que no se discute si una regla debe aplicarse al caso concreto, sino frente a la existencia de valores constitucionales en conflicto. En ese supuesto, se prioriza la aplicación de un principio, pero no implica que el otro principio se excluya del ordenamiento jurídico. En el caso concreto, hay un valor constitucional que debe privilegiarse.

Según Rubio Correa, este mecanismo busca evitar la arbitrariedad en la resolución de disputas constitucionales, pero no debe olvidarse que la valoración que se hace de los principios responde a contextos políticos y sociales específicos (2017, pp. 256-257). En ese orden de ideas, resulta legítimo que el principio de seguridad jurídica se vea limitado en un caso concreto si existe un fin legítimo de acuerdo a las finalidades del Estado Constitucional de Derecho.

Al haber un conflicto entre el principio de igualdad y el principio de la seguridad jurídica por la aplicación de la PDCT, es necesario someter a un test de ponderación esta norma para verificar la constitucionalidad de esta medida. De acuerdo al TC, el test de ponderación tiene tres etapas: idoneidad, necesidad y proporcionalidad en sentido estricto. Procedemos a explicar lo que dijo el TC por cada etapa y analizar cada una de ellas: (i) idoneidad; (ii) necesidad; $y$, (iii) proporcionalidad en sentido estricto o ponderación (Expediente 579-2008-PA/ TC, 2008).

- En primer lugar, "la idoneidad busca acreditar la adecuación del medio empleado por la ley con los fines perseguidos por ella" (Expediente 579-2008-PA/TC, 2008).
La PCDT cumple con el objetivo que persigue. A través de este mandato, la RD o RM que fue notificada dentro del plazo de prescripción para determinar la deuda por parte de la SUNAT surte efectos; es decir, genera un nuevo plazo para que la Administración tributaria pueda exigir el cobro de la deuda notificada. Por lo tanto, la PDCT sí es idónea.

- En segundo lugar, en lo relacionado a la necesidad, "una injerencia en los derechos será necesaria cuando no exista ningún otro medio alternativo que revista, por lo menos la misma aptitud para alcanzar el objetivo propuesto y que sea más benigna con el derecho afectado" (Expediente 579-2008-PA/TC, 2008).

A la fecha, no existe un mecanismo alternativo más benigno con el principio afectado (seguridad jurídica). Hay una resolución de observancia obligatoria emitida por el TF que impedía a la SUNAT, según el artículo 154 del CT, interponer una demanda contencioso administrativo contra ese precedente administrativo. Esta situación impedía que el Poder Judicial pueda analizar y pronunciarse sobre el tema materia de discusión.

De esta forma, la única medida razonable para evitar que se aplique de forma general el precedente de observancia obligatoria del TF era publicar la PDCT que contradice el criterio del TF.

- $\quad$ En tercer lugar, con respecto a la proporcionalidad en sentido estricto o ponderación, "el grado para que una injerencia en los derechos fundamentales sea legítima depende del grado de realización del objetivo de intervención, el cual debe ser por lo menos equivalente o proporcional al grado de afectación al derecho fundamental" (Expediente 579-2008-PA/TC, 2008).

Queremos hacer notar que la afectación del principio de seguridad jurídica es mínima. Antes de la entrada en vigencia del numeral 7 del artículo 44 del CT, las empresas sabían que la notificación de una RD o RM generaba el reinicio del cómputo del plazo de prescripción. No resulta cierto afirmar que la modificación del Decreto Legislativo 1113 generó una regulación distinta de la prescripción.

Por otra parte, la utilidad por la aplicación de la PDCT es proporcional a la afectación al principio de seguridad jurídica porque permite evitar que se genere una situación desigual para los deudores tributarios. 
La PDCT busca la legitimación del sistema jurídico tributario. A través de esta norma, el Estado busca que todos los contribuyentes que se encuentren en las mismas condiciones contribuyan al sostenimiento de las cargas públicas sin privilegios indebidos. De esa forma, se fortalece la confianza entre el Estado y los ciudadanos al imponer un sistema tributario con justicia.

Pues bien, al soportar la PDCT el test de ponderación, resulta constitucional su aplicación, pese a que, prima facie, aparecería afectando al principio de seguridad jurídica. En este sentido, el TC no debe declarar la inconstitucionalidad de esta norma.

\section{CONCLUSIONES}

- A partir de una interpretación sistemática de los artículos sobre prescripción, el plazo de prescripción para exigir el cobro de la deuda determinada por la SUNAT solo procede luego de que la Administración tributaria notifique la RD o RM. No resulta válido asumir que el plazo de prescripción para cobrar la deuda declarada por el contribuyente y la deuda determinada por la SUNAT es la misma.

- $\quad$ La PDCT no ordena la aplicación retroactiva del numeral 7 del artículo 44 del CT, sino que tiene como fundamento la aplicación de la teoría de los hechos cumplidos.

- El hecho relevante (notificación de la RD o de la RM) que origina el nuevo inicio del cómputo del plazo de prescripción para exigir el cobro de la deuda tributaria se produce desde la entrada en vigencia del Decreto Legislativo 1113 (28 de setiembre de 2012), es decir, la norma no genera consecuencias para los hechos relevantes producidos antes de la entrada en vigencia de la norma.

- $\quad$ La PDCT es una norma interpretativa. En estricto, esta norma no innova en el ordenamiento jurídico.

- $\quad$ La posición del TF sobre la PDCT, expresada en la Resolución 09789-4-2017, es incorrecta por dos motivos: (i) no diferencia entre el plazo de prescripción para exigir el pago de la deuda declarada por el contribuyente y el plazo para cobrar la deuda determinada por la SUNAT; y, (ii) el plazo para exigir el cobro solo puede derivar lógicamente después de la notificación de la RD o de la RM.

- La Corte Superior, en un caso similar (Expediente 07461-2015-0-1801-JR-CA-20), con- sidera que la aplicación del numeral 7 del artículo 44 del CT era aplicable al supuesto en el que se notifica una RM, luego de la entrada en vigencia del Decreto Legislativo 1113 , mientras el plazo de prescripción para aplicar la sanción no prescribe. La Corte Superior diferencia entre el plazo de prescripción para aplicar sanciones y el plazo de prescripción para cobrar las deudas de las RM. En este caso, se considera que no hay una aplicación retroactiva del numeral 7 del artículo 44 del CT.

- $\quad$ En el supuesto de que la PDCT mande una aplicación retroactiva del numeral 7 del artículo 44 del $\mathrm{CT}$, aplicando el test de ponderación entre el principio de igualdad y el de seguridad jurídica, dicha medida sería constitucional porque busca evitar la obtención de un privilegio indebido para un grupo de deudores tributarios.

No existe una afectación al principio de prohibición de abuso del derecho porque el conflicto jurídico no deviene por una conducta abusiva o fraudulenta de los deudores tributarios, sino por la aplicación en el tiem-

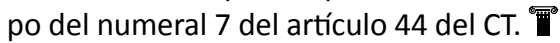

\section{REFERENCIAS}

Comisión Internacional de Juristas (2014). Prescripción e imprescriptibilidad. En Andreu-Guzmán, F. (Coord.) Derecho Internacional y Lucha contra la impunidad: Guía para profesionales 7 (pp. 383-386). Ginebra: ICJ.

Congreso de la República del Perú (2019). Informe 90/2018-2019 elaborado por el Grupo de Trabajo encargado del Control Constitucional sobre los actos normativos del Poder Ejecutivo. Recuperado de http://www.congreso.gob.pe/ Docs/comisiones2018/ConstitucionReglamento/files/informe_090_-_dl_1421.pdf

Durán Rojo, L. (2004). La noción del deber constitucional de contribuir. Revista Enfoque Constitucional, (1), p.13.

Hernández Berenguel, L. (2006). Apuntes para una nueva propuesta sobre prescripción y caducidad de la deuda tributaria. En Chau Quispe, L. (coord.). Temas de Derecho Tributario y de Derecho Público - libro homenaje a Armando Zolezzi Möller (pp. 445-446). Lima: Palestra Editores.

Organización de las Naciones Unidas (2019). World Economic Situation and Prospects 2019. Recuperado de https://unctad.org/en/PublicationsLibrary/wesp2019_en.pdf 
Rubio Correa, M. (1987). Prescripción, caducidad y otros conceptos en el nuevo Código Civil. Lima: Editorial Fundación M.J. Bustamante de la Fuente.

(2013). Aplicación de la Norma Jurídica en el Tiempo. Lima: Fondo Editorial de la PUCP.

(2017). La interpretación de la Constitución según el Tribunal Constitucional. Lima: Fondo Editorial de la PUCP.

Rubio Correa, M. y Arce Ortiz, E. (2017). Teoría esencial del ordenamiento jurídico peruano. Lima: Fondo Editorial de la Pontificia Universidad Católica del Perú.

Savigny, F. K. von (1897). Sistema del derecho romano actual. Madrid: Centro Editorial de Góngora.

Tribunal Fiscal del Perú (2017). Acta de Reunión de Sala Plena 2017-17.

Valdés Costa, R. (2013). Curso de Derecho Tributario. Montevideo: $\mathrm{B}$ de $\mathrm{F}$ Ltda.

Vidal Ramírez, F. (2002). Prescripción Extintiva y Caducidad. Lima: Editorial Gaceta Jurídica.

\section{LEGISLACIÓN, JURISPRUDENCIA Y OTROS DOCU- MENTOS LEGALES}

Decreto Legislativo 1113. Decreto Legislativo que modifica el Texto Único Ordenado del Código Tributario Diario Oficial El Peruano, 5 de julio de 2012.

Decreto Legislativo 1421. Decreto Legislativo que modifica el Código Tributario aprobado por Decreto Supremo 135-99-EF y normas modificatorias. Diario Oficial El Peruano, 13 de setiembre de 2018.

Decreto Legislativo 816. Decreto Legislativo que aprueba el Código Tributario. Diario Oficial El Peruano, 21 de abril de 1996.

Decreto Supremo 133-2013-EF. Texto Único Ordenado del Código Tributario. Diario Oficial EI Peruano, 22 de junio de 2013.
Decreto Supremo 263-H. Diario Oficial El Peruano, 12 de agosto de 1966.

Poder Judicial [Perú]. Tercera Sala de Derecho Constitucional y Social Transitorio de la Corte Suprema de Justicia de la República. Recaída en sentencia de casación 8312-2015, de 21 de noviembre del 2018.

Sétima Sala Especializada en lo Contencioso Administrativo con subespecialidad en materia tributaria y aduanera de la Corte Superior de Lima. Sentencia recaída en el expediente 07461-2015-0-1801-JR-CA-20, de 14 de noviembre de 2016 .

Tribunal Constitucional [Perú]. Sentencia recaída en el expediente 1157-98-AA-TC, del 30 de octubre de 1998.

Sentencia recaída en el expediente 0016-2002Al/TC, del 30 de abril de 2003.

Sentencia recaída en el expediente 0004-2004Al/TC, del 14 de mayo de 2004.

Sentencia recaída en el expediente 002-2006PI/TC, de 17 de mayo de 2007.

Sentencia recaída en el expediente 579-2008PA/TC, de 5 de junio de 2008.

Sentencia recaída en el expediente 052962007-PA/TC, de 10 de junio de 2010.

Sentencia recaída en el expediente 0024-2010$\mathrm{PI} / \mathrm{TC}$, de 21 de marzo de 2011.

Sentencia recaída en el expediente 024072011-PHC/TC, de 10 de agosto de 2011.

Sentencia recaída en el expediente 00037 2012-PA/TC, de 25 de enero de 2012.

Sentencia recaída en el expediente 026772014-PHC/TC, de 21 de enero de 2016.

Sentencia recaída en el expediente 015422015-PHC/TC, de 25 de mayo de 2016. 